\title{
Comparison of embolectomy outcomes for acute lower limb ischemia between patients aged $\geq 80$ years and $<80$ years
}

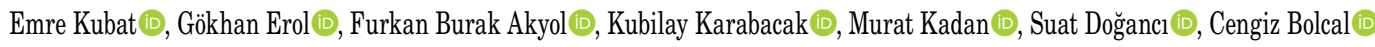 \\ Department of Cardiovascular Surgery, Health Sciences University Gülhane Training and Research Hospital, Ankara, Turkey
}

\begin{abstract}
Objectives: This study aims to compare embolectomy results for acute lower limb ischemia (ALLI) between patients aged $\geq 80$ years and $<80$ years.

Patients and methods: A total of 65 patients ( 39 males, 26 females; mean age, $70.2 \pm 17.9$ years; range, 20 to 94 years) who were diagnosed with ALLI and underwent urgent thromboembolectomy in our hospital between December 2016 and August 2018 were retrospectively analyzed. The patients were divided into two groups according to their age as $\geq 80$ years (Group 1 ) and $<80$ years (Group 2 ). Data including baseline demographic and clinical characteristics and postoperative data were recorded.

Results: There was a male predominance in Group 2, while the majority of patients were females in Group 1. Of the patients, 29 (44.6\%) were operated from the right lower limb, 32 (49.2\%) from the left lower limb, and four (6.2\%) bilaterally. There was no significant difference in the rate of postoperative hematoma, wound infection, compartment syndrome, acute renal insufficiency, amputation, and early mortality between the groups. However, the rate of amputation was statistically significantly higher in Group 2 with late presentation, than Group 1.

Conclusion: Our study results show similar results of urgent surgical thromboembolectomy between over and under 80 -year-old patients with ALLI. We believe that the age of the patient should not be an exclusion criterion for embolectomy due to ALLI.
\end{abstract}

Keywords: Amputation, embolectomy, ischemia, lower extremity.

Acute limb ischemia (ALI) is a sudden tissue perfusion blockade which leads to local ischemia and endangers the affected extremity, putting the patient's life at risk if left undiagnosed and untreated early. ${ }^{[1]}$ The rate of limb loss in ALI is about $40 \%$ with a high mortality rate ranging between 15 and $20 \% .{ }^{[2]}$ Despite recent developments in the revascularization techniques and intensive care, the mortality rates are still high, probably due to aging population and an increased atherosclerotic burden..$^{[1,3]}$

The majority of patients with ALI are elderly with multiple comorbidities. ${ }^{[1]}$ Increased life expectancy in many societies has increased the number of patients requiring emergency surgery. However, it is difficult to develop precise treatment guidelines for this patient population, although non-surgical conservative treatment modalities are associated with high morbidity and mortality rates. Previous studies have suggested that surgery yields less satisfactory outcomes in elderly with ALI who are preoperatively considered ineligible for surgery. ${ }^{[4,5]}$

In the present study, we aimed to compare embolectomy results for acute lower limb ischemia (ALLI) between patients aged $\geq 80$ years and $<80$ years.

Received: January 11, 2020 Accepted: January 21, 2020 Published online: March 11, 2020

Correspondence: Emre Kubat, MD. SBÜ Gülhane Eğitim ve Araştırma Hastanesi Kalp ve Damar Cerrahisi Kliniği, 06010 Etlik, Ankara, Türkiye. e-mail: ekubat@gmail.com Turk J Vasc Surg 2020;29(2):84-89

Part of this study was presented as poster presenteation in $20^{\text {th }}$ Congress of Turkish National Society of Vascular and Endovascular Surgery, Girne, Turkish Republic of Northern Cyprus, October 2019 


\section{PATIENTS AND METHODS}

This single-center, retrospective study included a total of 65 patients (39 males, 26 females; mean age, $70.2 \pm 17.9$ years; range, 20 to 94 years) who were diagnosed with ALLI and underwent urgent thromboembolectomy in our hospital between December 2016 and August 2018. Acute lower limb ischemia was defined as a sudden decrease in limb perfusion and the onset of ischemic symptoms within 14 days of presentation. The diagnosis of acute thromboembolism was made based on the physical examination and Doppler ultrasound (DUS) findings and confirmed by computed tomography angiography (CTA). Those who were scheduled for follow-up with medical treatment and those with dissection and trauma were excluded from the study. The patients were divided into two groups according to their age as $\geq 80$ years (Group 1 ) and $<80$ years (Group 2 ). The study protocol was approved by the local Ethics Committee (Dated 22.10.2019 with decision no: 19/348). The study was conducted in accordance with the principles of the Declaration of Helsinki.

Data including baseline demographic and clinical characteristics such as age, sex, comorbidities, thrombus localization and postoperative data such as biochemical test results, the presence of acute kidney injury (AKI), amputation, wound infection, and hematoma were recorded. Acute kidney injury was defined as over one-and-a-half-fold of baseline serum creatinine levels. Early mortality (defined as death within 30 days postoperatively) was evaluated. Time from the symptom onset to the emergency admission was recorded and presentations more than eight hours were considered late. ${ }^{[3]} \mathrm{A}$ written informed consent was obtained from each patient for surgical procedure. All data were retrieved from the hospital automation system and patient files.

\section{Surgical technique}

In all patients who underwent femoral embolectomy, the surgical technique and steps were identical. All patients were operated under local anesthesia using prilocaine 2\% (Priloc, Idol Pharmaceuticals, Istanbul, Turkey). Mild sedation with midazolam ( $2 \mathrm{mg}$ bolus) was used to relieve anxiety and pain. A vertical groin incision centered over the femoral artery below the inguinal ligament was used and the common femoral artery along with the superficial femoral artery and profunda femoris artery were dissected and looped with the cotton umbilical tapes. After heparinization at a dose of $1 \mathrm{mg} / \mathrm{kg}$, vascular clamps and bulldog clamps were applied proximally and distally over the common femoral artery with the superficial femoral artery and profunda femoris artery. A transverse arteriotomy was made on the common femoral artery, and Fogarty catheters of No. 3, 4, and 5 were used for extraction of the clots proximally and distally. Arteriotomy was, then, repaired with polypropylene suture 6-0. Hemostasis and standard closure were done.

\section{Postoperative follow-up}

Adjuvant intravenous sodium heparin administration or low-molecule-weight heparin (LMWH) was continued for one to three days after the operation. Subsequently, warfarin treatment was started in case of atrial fibrillation or other pre-existing conditions (e.g., mechanic cardiac valve replacement). Antiplatelet therapy (aspirin $100 \mathrm{mg}$ for times a day and/or clopidogrel $75 \mathrm{mg}$ for times a day was continued in the remaining patients.

\section{Statistical analysis}

Statistical analysis was performed using the SPSS version 11.0 software (SPSS Inc., Chicago, IL, USA). Continuous variables were expressed in mean \pm standard deviation $(\mathrm{SD})$ or median (min$\max$ ), while categorical variables were expressed in number and percentage. The Student's t-test was used to analyze significant differences between normally distributed data, while the Mann-Whitney $\mathrm{U}$ test was used to analyze non-normally data. The chi-square and Fisher exact tests were used to examine quantitative variables. A $p$ value of $<0.05$ was considered statistically significant.

\section{RESULTS}

Of the patients, 24 (37\%) were Group 1 and 41 (63\%) were Group 2. There was a significant difference in the age and sex between the groups $(\mathrm{p}<0.001)$. The mean age was $87.6 \pm 4.2$ (range, 80 to 94 ) for Group 1 and $60 \pm 14.5$ (range, 20 to 78) for Group 2. There was a male predominance among Group 2, while the majority of patients were females among Group 1 (Table 1).

Atrial fibrillation (AF) was seen in 40 , diabetes mellitus (DM) in 19 , hypertension in 29 , and chronic obstructive pulmonary disease (COPD) in 12 patients. There was no significant difference in the rate of comorbidities between the groups, except COPD $(p=0.045)$. Based on the DUS and CTA findings, thrombus was most commonly located in the femoral 
Table 1. Preoperative characteristics of the patients

\begin{tabular}{|c|c|c|c|c|c|c|c|c|c|}
\hline & \multicolumn{4}{|c|}{ Group 1 ( $\geq 80$ years) } & \multicolumn{4}{|c|}{ Group 2 (<80 years) } & \multirow[b]{2}{*}{$p$} \\
\hline & $\mathrm{n}$ & $\%$ & Mean $\pm S D$ & Range & $\mathrm{n}$ & $\%$ & Mean $\pm S D$ & Range & \\
\hline Age (year) & & & $87.6 \pm 4.2$ & $80-94$ & & & $60 \pm 14.5$ & $30-78$ & $<0.001^{*}$ \\
\hline \multicolumn{10}{|l|}{ Gender } \\
\hline Male & 6 & 25 & & & 33 & 80.5 & & & $<0.001 \dagger$ \\
\hline Female & 18 & 75 & & & 8 & 19.5 & & & \\
\hline Extremity & & & & & & & & & $0.52 \ddagger$ \\
\hline Right & 9 & 37.5 & & & 20 & 48.8 & & & \\
\hline Left & 14 & 58.3 & & & 18 & 43.9 & & & \\
\hline Bilateral & 1 & 4.2 & & & 3 & 7.3 & & & \\
\hline Diabetes mellitus & 9 & 37.5 & & & 10 & 24.4 & & & $0.26 \dagger$ \\
\hline Hypertension & 14 & 58.3 & & & 15 & 36.6 & & & $0.09 \dagger$ \\
\hline Chronic obstructive pulmonary disease & 52 & 20.8 & & & 2 & 4.9 & & & $0.045 \dagger$ \\
\hline Coronary artery disease & 7 & 29.2 & & & 5 & 12.2 & & & $0.09 \dagger$ \\
\hline Atrial fibrillation & 16 & 66.7 & & & 24 & 58.5 & & & $0.52 \dagger$ \\
\hline
\end{tabular}

SD: Standard deviation; * Student T test; $\uparrow$ Chi-square test; $\uparrow$ Fischer's exact test.

artery $(55.1 \%)$, followed by the popliteal artery (31.9\%) and iliac artery (13\%) (Table 2). Of the patients, $29(44.6 \%)$ were operated from the right lower limb, 32 (49.2\%) from the left lower limb, and four (6.2\%) bilaterally. No significant difference in the affected side operated between the groups $(\mathrm{p}=0.52)$.

In addition, there was no significant difference in the rate of postoperative hematoma, wound infection, compartment syndrome, acute renal insufficiency, amputation, and early mortality between the groups (Table 3). Postoperative hematoma was seen in only one patient (2\%) in Group 1 . Wound infection was seen in five patients (8\%). All patients were treated with antibiotherapy and local debridement. Seven patients $(10.8 \%)$ had AKI. Of these patients, four (6.2\%) progressed to acute renal failure and three died. Renal functions improved with hemodialysis in one patient (1.5\%). Three patients (4.6\%) had compartment syndrome and were all in Group 2. These patients underwent amputation. In all amputated patients, motor and sensory loss were present at the time of admission. Among Group 2, two patients (3.1\%) who were amputated were 76 years old, while the other was 42 years old. The latter patient had a previous history of Buerger disease with late presentation after acute embolism. A total of 14 patients $(21.5 \%)$ had

\begin{tabular}{lcc} 
Table 2. Localization of the occlusion & & \\
\hline Localization & $\mathrm{n}$ & $\%$ \\
\hline Iliac artery & 9 & 13 \\
Femoral artery & 38 & 55.1 \\
Popliteal artery & 22 & 31.9 \\
Total & 69 & 100
\end{tabular}

late presentation cases, including eight in Group 2 and six in Group 1. According to late presentation, there was no significant difference in the mortality rate; however, we found a significant difference in the rate of amputations between the groups ( $p=0.29$ and $\mathrm{p}=0.001$, respectively). The rate of amputation was significantly higher in younger patients with late presentation, while there was no significant difference for older patients ( $p=0.005$ and $p=0.78$, respectively).

Mortality was seen in five patients $(7.8 \%)$ including one (1.5\%) in Group 2 and four (6.2\%) in Group 1. A 76-year-old patient was died from acute renal failure in Group 2, while two patients were died from acute renal failure and the other two from recurrent cerebral embolism in Group 1.

\section{DISCUSSION}

Acute ischemia is caused by sudden termination of the blood flow. When trauma and iatrogenic events

\begin{tabular}{|c|c|c|c|c|c|}
\hline & \multicolumn{2}{|c|}{$\begin{array}{c}\text { Group } 1 \\
(\geq 80 \text { years })\end{array}$} & \multicolumn{2}{|c|}{$\begin{array}{c}\text { Group } 2 \\
\text { (<80 years) }\end{array}$} & \multirow[b]{2}{*}{$p^{*}$} \\
\hline & $\mathrm{n}$ & $\%$ & $\mathrm{n}$ & $\%$ & \\
\hline Hematoma & 1 & 4.2 & 0 & 0 & 0.19 \\
\hline Infection & 1 & 4.2 & 4 & 9.8 & 0.41 \\
\hline Compartment syndrome & 0 & 0 & 3 & 7.3 & 0.18 \\
\hline Amputation & 5 & 20 & 3 & 6.8 & 0.11 \\
\hline Acute kidney injury & 3 & 16.7 & 4 & 9.8 & 0.33 \\
\hline Mortality & 4 & 16.7 & 1 & 2.4 & 0.06 \\
\hline Acute renal failure & 3 & 13 & 1 & 2.4 & 0.13 \\
\hline
\end{tabular}


are eliminated, there are two main reasons including arterial embolism and thrombosis. The differentiation of these entities is critical for the definitive diagnosis and prognosis of the disease, although it does not alter the treatment course. ${ }^{[3]}$ Acute arterial occlusion presents without symptoms of claudication or chronic obstructive arterial disease and usually occurs secondary to embolism. ${ }^{[3]}$ The location of thrombus is primarily the heart, although it may involve the atherosclerotic debris. ${ }^{[6]}$ The presence of AF is a risk factor for cardiac thrombus and previous studies have shown an $\mathrm{AF}$ rate of 62 to $66 \%$ in this patient population. ${ }^{[3,7,8]}$ Consistent with the literature, the overall rate of AF was $61.5 \%$ in our study and there was no significant difference between the groups.

Embolic occlusions are progressive, as secondary thrombi located in the proximal and distal of the occluded segment increase ischemia. As a result, urgent anticoagulation with intravenous calcium heparin is initiated to stabilize the lower limb and to prevent deterioration. In addition, LMWH is a valuable treatment in many settings and calcium heparin is highly preferable and reversal can be immediately achieved with protamine. ${ }^{[3,6]}$ In our routine practice, all patients admitted with ALI receive $\mathrm{LMWH}$ in the emergency setting and heparin is used for anticoagulation postoperatively. Similarly, a previous study showed that anticoagulation improved the embolectomy results. ${ }^{[9]}$ Also, the use of heparin for limb irrigation decreases prolonged ischemia and amputation level without any increase in the mortality rate. ${ }^{[10]}$

A detailed vascular examination is helpful to identify the level of occlusion with arterial pulse loss. However, a strong pulse may mask an occlusion at that level due to the water-hammer effect; thus, DUS is mandatory for the diagnosis. ${ }^{[3]}$ Duplex ultrasound can be also used to identify the level of arterial occlusion and vessel patency in patients with ALI. In recent years, next generation computed tomography devices are available in many emergency departments and useful to obtain high-resolution images. In particular, CTA has been widely adopted for the investigation of ALI in the emergency setting. In our routine practice, all patients undergo DUS and those with normal renal functions undergo CTA. These work-ups help us to identify an acute occlusion in the arterial bed and to determine its level before surgical planning.

Embolic materials usually result in occlusion in the arterial bifurcation sites, leading to stenosis. ${ }^{[3]}$ The femoropopliteal artery of the lower limb is the most commonly affected vessel. ${ }^{[1,3,11]}$ About 35 to $40 \%$ of peripheral embolism involve the femoral artery, while $14 \%$ involve the popliteal trifurcation site. ${ }^{[1,6]}$ Consistent with the literature, in our study, the femoral artery (55.1\%) was most commonly affected, followed by popliteal artery (31.9\%). The discrepancy in the rates between our study and previous findings can be attributed to the fact that only lower limb embolisms were evaluated in our study. In particular, when embolic ischemia affects normal arteries without collateral circulation, it has poor prognosis. Collateral circulation is usually inadequate in younger patients, which reduces the tissue endurance to ischemia in embolic events. Duration of symptoms is the main distinguishing feature in medical history. In case of acute embolism, ischemia longer than six hours following thromboembolism has been shown to be associated with adverse surgical outcomes, as irreversible muscle necrosis may occur within six to eight hours in severe ischemic conditions, if left untreated. ${ }^{[3,12]}$ In our study, similarly, the rate of amputation was significantly higher in younger patients with late presentation. Another study demonstrated that the rate of amputation was significantly higher in patients with late presentation (>72 hours); however, the authors concluded that each patient deserved a chance for embolectomy to reduce the limb loss rate. ${ }^{[13]}$

The introduction of Fogarty balloon catheter thrombectomy in 1963 dramatically simplified the surgical embolectomy which has become the mainstay of ALI surgery. ${ }^{[14]}$ Despite technological advances, open vascular reconstruction for ALI has a major risk for morbidity (20\%) and limb loss (22\%) even in modern series. ${ }^{[15]}$ In recent years, endovascular techniques have become popular for the treatment of ALI, although the initial endovascular treatment is considered relatively expensive. ${ }^{[16]}$ In a meta-analysis including six clinical studies, endovascular and surgical treatment approaches yielded similar short-term and long-term (12 months) mortality, amputation, and recurrent ischemia rates in patients with ALI. ${ }^{[17]}$ In another study, although catheter-mediated thrombolysis was considered a favorable alternative to open surgery, its complication rate was significantly higher with poor outcomes in elderly. ${ }^{[18]}$ In our clinic, conventional balloon catheter embolectomy is the first-line procedure for all age group patients with ALI and CTA is applied to the patients with normal renal functions, if indicated.

Most patients with ALI are elderly with multiple comorbidities. Therefore, all patients should be monitored for fluid-electrolyte balance, complete blood count, coagulation parameters, and renal, cardiac, and 
respiratory system. ${ }^{[19]}$ In addition, patients with critical limb ischemia should be evaluated to identify the extent of local venous acidosis ischemia-reperfusion injury. ${ }^{[19]}$ In particular, renal functions should be closely monitored in elderly patients and those with renal impairment before and after revascularization. ${ }^{[1,19]}$ Acid base imbalance or electrolyte abnormalities should be immediately corrected..$^{[1,3,6,19]}$ Elderly are more vulnerable to hemodynamic instability which makes them frail. Frailty is a common geriatric phenomenon making older individuals unguarded against acute stress. ${ }^{[20,21]}$ As a result, this population is more vulnerable to catastrophic declines in health and function and an elevated risk for long-term care requirement and mortality. ${ }^{[20]}$ Nonetheless, not all older individuals are equally frail. Considering frailty in routine medical care, clinicians should tailor treatment individually for each patient, as the degree of frailty may vary. ${ }^{[21]}$ In a previous study, the mortality rate was found to be significantly higher among the octogenarians than septuagenarians with critical lower limb ischemia, irrespective of the type of surgical procedure. ${ }^{[22]}$ Therefore, older age which decreases the life-expectancy should be considered particularly for elderly population.

Health status of a patient with ALI is a reliable survival prognostic factor. ${ }^{[23]}$ In particular, those with acute myocardial infarction or low cardiac output are at a higher risk for mortality. It has been well documented that ALI patients constantly require a high level of medical services with a 30-day amputation rate of 5 to $12 \%$ and a mortality rate of 10 to $38 \% \cdot{ }^{[23]}$ Furthermore, the mortality rate was found to be expectedly high in older patients with critical limb ischemia and one-year mortality rate was as high as $29 \%$, regardless of the treatment given. Late mortality rate was reported as $66 \%$ at five years, indicating a higher mortality rate compared to the general population. ${ }^{[2]}$ Some authors also found that the mortality risk was 15-times higher among octogenarians than non-octogenarians. ${ }^{[4,5]}$ Similarly, mortality was observed in five patients in our study and four of these patients were in elderly patient group. Although not statistically significant, the mortality rate was higher among the elderly patients. One patient in Group 1 was 76 years old, quite close to being an octogenarian. Despite recent technological advances, amputation rates in the hospital setting still remain high; however, the rate of late amputation tends to decline. Therefore, the amputation rate seems to be a more reliable predictor for the evaluation of postoperative events. ${ }^{[5]}$ This can be explained by the fact that the main goal of treatment in ALI is to salvage the affected limb and to improve quality of life. ${ }^{[2]}$ Although we observed no statistically significant difference in the amputation rate between the groups, it was significantly higher in the younger patients with late presentation.

Nonetheless, there are some limitations to this study. The retrospective nature of the study precludes elimination of all potential confounders and biases. Its single-center design conducted by a single specialty for selected patients is another limitation of the study. We also included only those in whom embolectomy was the first-line treatment. Finally, small sample size limits the ability to draw definitive conclusions. Despite all these limitations, we believe that the present study provides additional information to the body of knowledge on embolectomy among elderly with ALLI.

In conclusion, our study results showed similar results of urgent surgical thromboembolectomy between over and under 80-year-old patients with ALLI. Based on these findings, early diagnosis and active treatment using appropriate techniques for an individual patient are the keys to success. We believe that the age of the patient should not be an exclusion criterion for embolectomy due to ALLI.

\section{Declaration of conflicting interests}

The authors declared no conflicts of interest with respect to the authorship and/or publication of this article.

\section{Funding}

The authors received no financial support for the research and/or authorship of this article.

\section{REFERENCES}

1. Bozkurt AK. Akut bacak iskemisi. In: Bozkurt AK, editör. Periferik Arter ve Ven Hastalıkları. Ulusal Tedavi Kılavuzu 2016. İstanbul: Bayçınar Tıbbi Yayıncılık; 2016. s. 44-61

2. Norgren L, Hiatt WR, Dormandy JA, Nehler MR, Harris KA, Fowkes FG; TASC II Working Group. Inter-Society Consensus for the Management of Peripheral Arterial Disease (TASC II). J Vasc Surg 2007;45:S5-67.

3. Earnshaw JJ. Acute ischemia: Evaluation and decision making. In: Sidawy AN, Perler BA, editors. Rutherford's Vascular Surgery and Endovascular Therapy. 9th ed. Philadelphia: Elsevier; 2017. p. 4372-4404.

4. Zaraca F, Ponzoni A, Sbraga P, Ebner JA, Giovannetti $\mathrm{R}$, Ebner H. Factors affecting long-term outcomes after thromboembolectomy for acute lower limb ischemia. Minerva Chir 2012;67:49-57.

5. Piffaretti G, Angrisano A, Franchin M, Ferrario M, Rivolta N, Bacuzzi A, et al. Risk factors analysis of thromboembolectomy for acute thromboembolic lower extremity ischemia in native arteries. J Cardiovasc Surg 2018;59:810-6. 
6. Ouriel K. Acute Arterial Occlusion of the Lower Extremities. In: Ascer E, Veith FJ, Gloviczki P, editors. Haimovici's Vascular Surgery. 6th ed. Chichester: WileyBlackwell; 2012; 703-710.

7. Aldağ M, Öztekin A, Bademci MŞ, Kocaaslan C, Denli Yalvaç EŞ, Aydın E. Surgical results of acute thromboembolic limb ischemia in octogenarians. Damar Cer Derg 2018;27:111-6.

8. Galzerano G, de Donato G, Setacci F, Sirignano P, Sauro $\mathrm{L}$, Cappelli A, et al. Acute limb ischemia in nonagenarians. J Cardiovasc Surg 2013;54:625-31.

9. Campbell WB, Ridler BM, Szymanska TH. Two-year follow-up after acute thromboembolic limb ischaemia: the importance of anticoagulation. Eur J Vasc Endovasc Surg 2000;19:169-73.

10. Earnshaw JJ1, Whitman B, Foy C. National Audit of Thrombolysis for Acute Leg Ischemia (NATALI): clinical factors associated with early outcome. J Vasc Surg 2004;39:1018-25.

11. Amendt K, Schömig A, Wilhelm C, Hsu E, Weiss T, Diehm C, et al. Intravascular ultrasound (IVUS) in patients with peripheral arterial occlusive disease (PAOD). Vasa 1992;21:27-38.

12. Kempe K, Starr B, Stafford JM, Islam A, Mooney A, Lagergren E, et al. Results of surgical management of acute thromboembolic lower extremity ischemia. J Vasc Surg 2014;60:702-7.

13. Iyem H, Eren MN. Should embolectomy be performed in late acute lower extremity arterial occlusions? Vasc Health Risk Manag 2009;5:621-6.

14. Fogarty TJ, Cranley JJ. Catheter technic for arterial embolectomy. Ann Surg 1965;161:325-30.

15. Baril DT, Patel VI, Judelson DR, Goodney PP, McPhee JT,
Hevelone ND, et al. Outcomes of lower extremity bypass performed for acute limb ischemia. J Vasc Surg 2013;58:94956.

16. Lurie F, Vaidya V, Comerota AJ. Clinical outcomes and costeffectiveness of initial treatment strategies for nonembolic acute limb ischemia in real-life clinical settings. J Vasc Surg 2015;61:138-46.

17. Enezate TH, Omran J, Mahmud E, Patel M, AbuFadel MS, White CJ, et al. Endovascular versus surgical treatment for acute limb ischemia: a systematic review and meta-analysis of clinical trials. Cardiovasc Diagn Ther 2017;7:264-71.

18. Plate G, Oredsson S, Lanke J. When is thrombolysis for acute lower limb ischemia worthwhile? Eur J Vasc Endovasc Surg 2009;37:206-12.

19. Olinic DM, Stanek A, Tătaru DA, Homorodean C, Olinic M. Acute Limb Ischemia: An Update on Diagnosis and Management. J Clin Med 2019;8. pii: E1215.

20. Fried LP, Ferrucci L, Darer J, Williamson JD, Anderson G. Untangling the concepts of disability, frailty, and comorbidity: implications for improved targeting and care. J Gerontol A Biol Sci Med Sci 2004;59:255-63.

21. Xue QL. The frailty syndrome: definition and natural history. Clin Geriatr Med 2011;27:1-15.

22. Klaphake S, de Leur K, Mulder PGH, Ho GH, de Groot HGW, Veen EJ, et al. Life Expectancy and Outcome of Different Treatment Strategies for Critical Limb Ischemia in the Elderly Patients. Ann Vasc Surg 2018;46:241-8.

23. Ouriel K, Veith FJ. Acute lower limb ischemia: determinants of outcome. Surgery 1998;124:336-41.

24. Conte MS. Critical appraisal of surgical revascularization for critical limb ischemia. J Vasc Surg 2013;57:8S-13S. 